\title{
The Premium/Discount Of Closed-End Funds As A Measure Of Investor Sentiment: Evidence From Greece
}

Dimitrios V. Kousenidis, Aristotle University of Thessaloniki, Greece Dimitrios I. Maditinos, Kavala Institute of Technology, Greece Željko Šević, Glasgow Caledonian University, Scotland

\begin{abstract}
We examine the proposition that the premium/discount (PD) of Greek closed-end funds (CEFs) is an accurate proxy for the small-investor sentiment risk. We find that the average PD explains the returns of portfolios of large capitalization and low book-to-market ratio stocks. In this context, we are unable to confirm a link between the perceived PD anomaly and the small size effect. Moreover, we show that the explanatory power of the PD for portfolio returns depends on the form of the asset pricing model used in the regression analysis. Finally, in terms of predictive ability, we find evidence that the PD predicts the size and the book-to-market premiums but little evidence that the $P D$ predicts individual portfolio returns.
\end{abstract}

Keywords: closed-end funds; premium/discount; small investor sentiment; size; book-to-market ratio; portfolio returns

\section{INTRODUCTION}

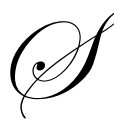

everal researchers in finance have entered on both sides of the long-running argument as to whether (or not) the premium/discount (PD henceforth) of closed-end funds (CEFs) reflects individual investor sentiment, defined as the propensity to speculate ${ }^{1}$. On one side, many researchers provide evidence favoring the behavioral explanation of Lee et al. (1991) and Chopra et al. (1993a,b) which states that the PD of CEFs captures the sentiment risk premium that affects the prices of stocks held by individual investors and especially those of CEFs and of small size stocks. On the other side, many researchers support the fundamental view of Chen et al. (1993a,b) and present evidence that the PD of CEFs fails to represent an additional sentiment risk factor that requires pricing.

In the present paper, we used monthly data for Greek firms over the period from January 1997 to December 2007 to test the hypothesis that the PD of Greek CEFs is an accurate measure of the small-investor sentiment risk. We found that the average PD exhibits some degree of explanatory power for the returns of decile portfolios sorted according to size and to book-to-market ratio. Like Brown and Cliff $(2004,2005)$ we report a stronger relation between the PD and the returns of large capitalization and low book-to-market stocks than between the PD and the returns of small capitalization and high book-to-market stocks. Hence we are unable to confirm a link between the perceived PD anomaly and the small size effect.

We also show that the explanatory power of the PD for portfolio returns depends on the form of the asset pricing model used in the regression analysis. In particular, similarly to Elton et al. (1998) we document that when moving from a single-factor regression model (i.e., the Sharpe-Lintner CAPM) to a multi-factor regression model (i.e., the Fama-French CAPM) the slope coefficient of the PD decreases in both size and significance. Moreover, the PD appears to exhibit marginal incremental explanatory power over the mimicking factor portfolio which relates to the book-to-market ratio. 
In terms of predictive ability, we examined whether the PD complies with the behavioral model of sentiment which predicts that periods of high sentiment are followed by periods of low stock returns. Consistent with prior research by Neal and Wheatley (1998) and Baker and Wurgler (2006) we report evidence indicating that the PD significantly predicts near-term reversals in the size and the book-to-market premiums (i.e., the returns of hedge portfolios which are long on stocks with small capitalization and high book-to-market ratios and short on stocks with large capitalization and low book-to-market ratios respectively). However, unlike prior research, we were unable to demonstrate that the PD has the power to predict near-term reversals in individual portfolio returns.

In the present paper we provide the first comprehensive Greek study on the PD of CEFs as a measure of sentiment risk. The results we report are based on a broad unbalanced panel dataset over a long period of time and support that the PD of Greek CEFs complies with some of the predictions of the behavioral model for small investor sentiment; however, it fails to properly capture the potential effects of sentiment risk on the level of asset prices. Our findings also reconcile some of the conflicting results of the few earlier Greek studies on investor sentiment. In particular, Doukas and Milonas (2004) reported that the PD of Greek CEFs as a proxy for sentiment risk does not significantly enter the return generating process. Hardouvelis et al. (2004), on the other hand, found many commonalities in the behavior of the PD of Greek CEFs with the respective of their US counterparts implying that the PD anomaly applies also in smaller and less developed markets. Finally, Halkos and Krintas (2006) showed that the PD of Greek CEFs correlates with several other widely advocated behavioral factors and concluded that it is possible to explain the variability in PD within the context of the investor sentiment model.

Our results are important for (at least) two reasons. First, most of the evidence for the investor sentiment anomaly has been reported in the context of large and developed capital markets. However, if sentiment is a psychological risk factor, its impact on asset pricing is expected to be more profound in highly fluctuating emerging markets where small investors are more susceptible to noise trading. The Greek capital market is one such market. As a striking example, we note that during the bubble of 1999 the number of active investors was ten times as much as it was three years later.

Second, in a thorough review of the behavioral anomalies literature, Fama (1998) examined whether several anomalies tend to persist over time and over various settings and recognized the scarcity of out-of-sample evidence for most of them. Hence, our results contribute to the existing literature by providing another piece of outof-sample evidence for a long-puzzling anomaly.

The remainder of our paper is organized as follows. In section 2 we provide a review of the literature on small investor sentiment. In section 3 we describe our data set and expand on our methodological procedure. In section 4 we present and analyze our empirical findings. Finally, in section 5 we conclude the paper and offer some implications for further research.

\section{THE PD OF CEFS AND THE SMALL INVESTOR SENTIMENT}

The premium or discount (PD) of the market prices of closed-end funds (CEFs) to the net asset values of the equities owned by the funds has been, over the past thirty years, one of the most-researched anomalies within the context of the theory of efficient capital markets. The early research in the area went along with the guidelines of the Efficient Markets Hypothesis (EMH) and offered a plethora of economic explanations for the existence of the PD phenomenon. Many such explanations were thoroughly reviewed by Dimson and Minio-Paluello (2002), including Net Asset Values (NAV) miscalculations, agency costs associated with managerial over or underperformance, and omitted equity risk premiums relating to market segmentation when CEFs try to diversify internationally.

However, the failures of several attempts to prove that these explanations are sufficient and generally applicable to cross-country institutional environments (i.e., Gemmill and Thomas, 2000) have directed the interest of researchers toward behavioral explanations of the PD phenomenon. In particular, De Long et al. (1990) and Lee et al. $(1990,1991)$ took a stand opposite to the EMH and assumed that small investors are not rational but rather noisetraders who make their investment decisions according to their sentiment instead of according to the axiom of expected utility maximization. Therefore, their forecasts about future cash flows are not always unbiased and the prevailing sentiment bias has a material effect on the equity risk premium. 
In addition, Lee et al. (1991) showed that the PDs are not fund-specific but rather they tend to move coordinately. They also demonstrated that changes in the average PD of CEFs capture the investor sentiment risk premium which affects the prices of stocks held by individual investors and especially those of CEFs and of small size stocks. The other side of their story assumed that rational investors are aware of the fact that betting against sentimental investors is both costly and risky and therefore they abstain from engaging in arbitrage strategies which would eliminate the mispricing of stocks. Thus, the premium (discount) of CEFs is not driven by the optimism (pessimism) of irrational investors, but arises completely from the risk aversion of rational investors (arbitrageurs) to buy closed-end fund shares unless they are compensated for the sentiment risk which cannot be diversified away.

While the research in the area is still ongoing, the reported results have raised several conflicting arguments. At one extreme, there is evidence in favor of the PD anomaly and of its link with the small firm effect ${ }^{2}$. For example, Severn (1998) showed that sentiment explained both the closed-end fund puzzle and the small firm effect. He found that diversifying across closed-end funds does not reduce sentiment risk because discounts are correlated across funds. Moreover, he presented evidence that diversification between closed-end funds and largecapitalization-stocks reduces sentiment risk, especially when markets are not subject to major shocks.

Ljungqvist et al. (2006) related small investor sentiment to another perceived market anomaly, IPO underpricing. They claimed that IPOs are underpriced even in hot-market times because rational investors expect these periods to end prematurely. Therefore, stocks must be underpriced in order for rational investors to gain from trading with sentimental investors in the short-lived bullish post-IPO period. However, issuing firms also realize gains because the offering price capitalizes part of the expected trading gain of rational investors. This explanation resolves the paradox that issuing firms, while timing their IPO to take advantage of optimistic valuations, appear not to price their stocks very aggressively.

Bodurtha et al. (1995), Levis and Thomas (1999), Brown et al. (2002), and Simpson and Ramchander (2002) provided evidence suggesting that the PD is not only a single market-specific sentiment risk factor but it can also affect foreign country funds which are traded in the particular domestic market, implying that apart from the domestic sentiment risk there is also a specific local sentiment risk that is reflected in foreign country funds.

In terms of return predictability, Brown (1999) and Gerber et al. (2002) showed that individual investor sentiment displays sufficient explanatory power for the excess volatility of closed-end fund returns. Moreover, Gerber et al. (2002) showed that sentiment can also explain the short-term momentum and the long-term reversals in stock returns.

Baker and Wurgler $(2006,2007)$ used six different proxies of sentiment (PD is one of them) to calculate a composite sentiment index and examine how investor sentiment affects the cross-section of stock returns. They showed that their sentiment index explains and exhibits some degree of predictive ability for the return patterns of small capitalization stocks, highly volatile stocks, unprofitable stocks, non-dividend-paying stocks, extreme-growth stocks and distressed stocks. These results appear to be consistent with the theoretical predictions for the movement of these stocks and according to Baker and Wurgler cannot be explained by the assumption that investors require additional compensation for systematic risk factors.

At the other extreme, there is evidence which fails to fully support the behavioral explanations of the PD anomaly. Shortly after its publication, the paper of Lee et al. (1991) was seriously attacked by Chen et al. (1993a,b). What Chen et al. believe is that the findings of Lee et al. lack statistical significance and robustness and therefore are unable to support the need to include an additional sentiment risk factor in asset pricing models. In a similar vein, Leonard and Shull (1996) attributed the correlated movement in the returns of CEFs to a January seasonal effect on the returns of both CEFs and small-capitalization firms. For the period from 1965 to 1980 they reported a sentiment risk factor in common stock returns which was found to be significant even when controlling for the January effect. However, they observed that in the post-1980 period the institutional activity for small capitalization stocks has displayed a significant increase and the sentiment risk vanishes after controlling for the January effect, implying that the PD anomaly is at best transitory.

Neal and Wheatley (1998), on the other hand, demonstrated that even when controlling for the January effect, the PD of CEFs strongly relates to the returns of small-capitalization firms. However, they failed to document 
a significant relation between the PD and the returns of large-capitalization firms. These relations were also shown to extend to the predictive ability of the PD and their final results suggested that the PD could adequately predict the size premium, i.e., the differential return between small-capitalization and large-capitalization stocks.

Elton et al. (1998) considered whether the PD consists of a sentiment risk factor which should be priced in an equilibrium asset pricing framework. What they believe is that in certain cases sentiment risk consists of an important risk factor ${ }^{3}$. However, they questioned whether the PD adequately proxies for the small investor sentiment which is priced in the returns of common stocks. Elton et al. showed that when the PD is included in a single-factor asset pricing model then it is a significant risk factor. However, when the PD is included in an augmented multifactor model, then the sentiment risk is found to be uncorrelated with the time series of returns of stocks or portfolios of stocks. Moreover, they showed that the PD is fully explained by influences unrelated to a sentiment index, and that the firms with higher sensitivity to the change in the PD do not on average yield higher returns.

Finally, Brown and Cliff $(2004,2005)$ showed that excessive optimism drives stock prices above intrinsic values, and that the periods of high sentiment are followed by periods of low returns as market prices revert to fundamental values. Contrary to the belief that sentiment affects mainly small-capitalization stocks, they found their relations to be stronger for large-capitalization portfolios and low book-to-market ratio (growth) portfolios. Finally, they showed that indirect factors which proxy for sentiment (such as the PD) are strongly related to direct sentiment measures (surveys) and to contemporaneous stock returns but display little predictive power for near-term market returns.

\section{RESEARCH DESIGN}

\section{The Data Set}

To carry out our empirical analysis we used three different sets of data. The first set consists of monthly data for an unbalanced sample of all Greek Industrial and Commercial firms ${ }^{4}$ listed in the Athens Stock Exchange (ASE) over a period of 132 months from 1/1/1997 to 12/31/2007. The sample includes both young and old firms as well as surviving and failing firms and therefore it is considered to be free of any survivorship bias. Moreover, in order to avoid the effects of IPO underpricing new listings were included in the sample on the third month after the IPO month.

For all firms in the sample monthly stock returns were obtained from the ASE database. The returns were adjusted for stock splits and share capital increases but they are net of any dividend payments. Moreover, for all sample firms monthly data for market capitalization (share price times number of common shares outstanding) and annual data for the book value of equity were also obtained. Book value of equity is net of preferred stock.

Market capitalization (MVE) is used as a proxy for firm size. Book value of equity (BVE) divided by market capitalization yields the ratio of book value of equity to market value of equity (BVE/MVE). To conform to the analysis of Fama and French (1993) we match BVE at the end of year $t-1$ to monthly MVE and stock returns from July $t$ through June $t+1$. Size and BVE/MVE calculated thus comprise the sample firm characteristics used to create decile style portfolios and to calculate the two mimicking risk factors of Fama and French $(1992,1993)$ which capture variations in the cross-section of average stock returns.

The second set of data was also obtained from ASE and included monthly returns of the Composite Price Index (CPI) of the ASE and monthly rates of the Three-Month Treasury Bill (3M T-Bill) of the Greek government. Returns of the CPI are net of dividends and approximate the returns of the market portfolio, while the 3M T-Bill rates approximate the risk-free rate of return.

The third set of data consists of an unbalanced panel of monthly NAV and market prices of all listed Greek CEFs over the period of investigation from 1/1/1997 to 12/31/2007. These data were used to calculate a weighted average PD of CEFs which proxies for the small investor sentiment risk factor. Data for closed-end funds are available free of charge on the website of the Association of Greek Institutional Investors (www.agii.gr). 


\section{Calculation of the Sentiment Factor} follows:

We calculate our investor sentiment index as in Lee et al. (1991) by taking a value-weighted index of PD as

$$
V W P D_{t}=\sum_{i=1}^{n} w_{i, t} P D_{i, t}
$$

where

$$
\begin{aligned}
& w_{i, t}=\frac{N A V_{i, t}}{\sum_{i=1}^{n} N A V_{i, t}} \\
& P D_{i, t}=\frac{S P_{i, t}-N A V_{i, t}}{N A V_{i, t}} \text {, is the percentage PD of CEF } \mathrm{i} \text { at the end of month } t .
\end{aligned}
$$

$\mathrm{NAV}_{\text {it }}$ is the Net Asset Value of CEF $i$ at end of month $t$.

$\mathrm{SP}_{\mathrm{it}}$ is the Stock Price of CEF $i$ at the end of month $t$, and

$\mathrm{n}$, is the number of CEFs with available $\mathrm{PD}_{\mathrm{it}}$

$\mathrm{VWPD}_{t}$ is hypothesized to be directly related to sentiment. That is, in periods of high sentiment $\mathrm{VWPD}_{\mathrm{t}}$ should be able to expose common stock overvaluation and to forecast consecutive low stock returns (Baker and Wurgler, 2006).

\section{Portfolio Formation}

To capture the effects of cross-sectional variations in expected returns and risk we classified sample firms into equally-weighted decile portfolios according to the styles of size and BVE/MVE. Our decision to form equally weighted portfolios was motivated by Baker and Wurgler (2006) who suggested that large firms are less affected by sentiment and therefore value weighting makes the return patterns difficult to explain. Moreover, in order to comply with a model of individual investors' active trading behavior (i.e., Merikas et al., 2004; Maditinos et al., 2007; Calvet et al., 2008) and in order to avoid the effects of momentum patterns in portfolio returns, we rebalanced our portfolios at the beginning of every month throughout the entire period of investigation. Then for each one of the twenty style portfolios we calculated equally-weighted portfolio returns at the end of the month of portfolio formation.

The size decile portfolios were formed by sorting firms according to their market capitalization at the beginning of each month. Portfolio S1 included firms of low capitalization (small size) and portfolio S10 included firms of large capitalization (big size). The number of stocks in the portfolios varied across months. The decile portfolios formed according to size have the advantage that they control for changes in MVE which have been shown to be associated with expected returns and risk (i.e., Banz ,1981; Fama and French, 1992). Another advantage of the size portfolios is that they allow us to examine whether there is a link between the small investor sentiment effect and the firm size effect (Lee et al., 1991; Severn, 1998; Baker and Wurgler, 2006 and 2007).

The book-to-market decile portfolios were formed in a similar manner by sorting sample firms according to their BVE/MVE ratio at the beginning of each month. Portfolio BM1 included low BVE/MVE stocks and portfolio BM10 included high BVE/MVE stocks. Again, the number of stocks in the portfolios varied from month to month. The book-to-market portfolios have the advantage that they allow us to examine how the expected returns and risk of high BVE/MVE stocks (value stocks) or low BVE/MVE stocks (growth stocks) change over the period examined (i.e., Lakonishok et al., 1994; Fama and French 1998). Moreover, further evidence suggests that by sorting firms 
into book-to-market portfolios it is possible to expose investor overreaction in good and bad market times (i.e., DeBondt and Thaler, 1987; Lakonishok et al., 1994). Finally, as the theory predicts, low book-to-market (growth) firms have relatively subjective valuations and are relatively hard to arbitrage. Hence they are expected to be most affected by small investor sentiment (Baker and Wurgler, 2006 and 2007).

\section{Calculation Of The Fama And French Factors}

We created the Fama and French mimicking risk factors by classifying sample firms into six intercept portfolios sorted first according to size and then according to the BVE/MVE ratio. Our approach was similar to that of Fama and French (1993). However, in order to conform to our decile portfolio approach we rebalanced the intercept portfolios on a monthly basis. In particular, at the beginning of each month we used the median capitalization as the cut-off point in order to classify sample firms into two value-weighted size portfolios: the smallsize portfolio, $\mathrm{S}$, and the big-size portfolio, $\mathrm{B}$. Each one of the two size portfolios was further divided into three BVE/MVE sub-portfolios according to the 40\%-20\%-40\% rule: the high BVE/MVE sub-portfolio, $\mathrm{H}$, the medium $\mathrm{BVE} / \mathrm{MVE}$ sub-portfolio, M, and the low BVE/MVE sub-portfolio, L.

For each one of the six intercept portfolios (SL, SM, SH, BL, BM and BH) we calculated value-weighted returns at the end of the month of portfolio formation. The average return of the mimicking factor portfolio that is related to size is the difference between the average return of the three small-size portfolios and the average return of the three big-size portfolios: $\mathrm{SMB}=(\mathrm{SL}+\mathrm{SM}+\mathrm{SH}) / 3-(\mathrm{BL}+\mathrm{BM}+\mathrm{BH}) / 3$. Similarly, the average return of the mimicking factor portfolio that is related to the BVE/MVE ratio is the difference between the average return of the two high BVE/MVE portfolios and the average return of the two low BVE/MVE portfolios: $\mathrm{HML}=(\mathrm{SH}+\mathrm{BH}) / 2-$ $(\mathrm{SL}+\mathrm{BL}) / 2$.

Table 1 tabulates summary descriptive statistics for the two Fama-French factors as well as for the VWPD, the return of the market portfolio and the risk-free rate of return. In contrast to the market, the SMB and the HML factors delivered negative mean and median returns implying that over the period examined big size and low BVE/MVE firms outperformed small size and high BVE/MVE firms respectively.

Table 1: Summary Descriptive Statistics of Control Variables

\begin{tabular}{|l|l|l|l|l|l|}
\hline & $\boldsymbol{V}$ PPD & $\boldsymbol{R}_{\boldsymbol{M}}$ & $\boldsymbol{R}_{\boldsymbol{F}}$ & $\boldsymbol{S M B}$ & $\boldsymbol{H} \boldsymbol{L}$ \\
\hline Mean & $-3.593 \%$ & $1.686 \%$ & $0.447 \%$ & $-1.046 \%$ & $-2.844 \%$ \\
\hline Median & $-10.552 \%$ & $1.495 \%$ & $0.342 \%$ & $-1.550 \%$ & $-2.675 \%$ \\
\hline Std. Dev. & $25.324 \%$ & $8.939 \%$ & $0.272 \%$ & $7.653 \%$ & $5.602 \%$ \\
\hline Kurtosis & 12.443 & 3.166 & -0.274 & 2.367 & 1.409 \\
\hline Skewness & 3.290 & 0.796 & 0.957 & 0.470 & -0.278 \\
\hline Min. & $-27.376 \%$ & $-22.231 \%$ & $0.168 \%$ & $-26.820 \%$ & $-22.820 \%$ \\
\hline Max. & $143.512 \%$ & $41.333 \%$ & $1.158 \%$ & $24.740 \%$ & $12.580 \%$ \\
\hline Count & 132 & 132 & 132 & 132 & 132 \\
\hline
\end{tabular}

Notes: VWPD is the value weighted average premium/discount of CEFs listed in the ASE; $R_{M}$ is the return on the ASE-GPI; $R_{F}$ is the monthly rate of the 3M-TBill of the Greek Government; SMB and HML are the Fama-French mimicking risk factors estimated for the ASE. Numbers are rounded to three decimal points.

We also estimated the correlation between the returns of the two Fama-French factors. As expected it was found to be quite small (0.11) implying that SMB is relatively unaffected by the BVE/MVE ratio effect and HML is relatively unaffected by the size effect. Hence the SMB and HML factors should enable us to document potential comovement of stocks corresponding to their styles (Fama and French, 1993). 


\section{Regression Models}

We considered a regression approach which allowed us to examine whether the PD of CEFs is able to explain cross-sectional variations in portfolio returns. Our first regression model was the univariate CAPM augmented by VWPD:

$R_{p, t}=a+\beta R_{M, t}+p V W P D_{t}+e_{p, t}$

where:

$\mathrm{R}_{\mathrm{p}, \mathrm{t}}$ is monthly excess portfolio return calculated as the difference between raw portfolio returns and monthly risk free rate of return,

$\mathrm{R}_{\mathrm{m}, \mathrm{t}}$ is excess market return calculated as the difference between raw market returns and the risk free rate of return,

and

VWPD $_{t}$ is the value weighted PD calculated as described above.

The testable hypothesis which relates to this model states that if VWPD captures the small investor risk factor, then $p$ is expected to have a positive sign and to be statistically significant. Moreover, its effects should be more profound for small size and low book-to-market portfolios.

Our second regression approach considered a model which allowed us to control for co-movement in stylesorted stocks by using the Fama and French factors:

$$
R_{p, t}=a+\beta R_{M, t}+s S M B_{t}+h H M L_{t}+p V W P D_{t}+u_{p, t}
$$

where $\mathrm{SMB}_{\mathrm{t}}$ and $\mathrm{HML}_{\mathrm{t}}$ are the Fama and French mimicking risk factors relating to size and BVE/MVE respectively and the rest of the variables are as described above.

The testable hypothesis which relates to our second model states that if VWPD is an economically significant sentiment risk factor that needs to be priced, then it should exhibit information content for portfolio returns which is not encompassed by other widely advocated risk factors. Put another way, its power in explaining portfolio returns should not be contingent upon the form of the Asset Pricing Model used (Elton et al., 1998; Doukas and Milonas, 2004).

We then turned our regression approach to a set of predictive regressions that allowed us to examine whether periods of high sentiment are followed by periods of low portfolio returns. Our predictive regressions shared many intuitive commonalities with those of Neal and Wheatley (1998) and of Baker and Wurgler (2006) and had the following form:

$$
\begin{aligned}
& R_{p, t}=a+c R_{p, t-1}+\sum_{T=1}^{3} p_{T} V W P D_{t-T}+\varepsilon_{p, t} \\
& R_{p, t}=a+\beta R_{M, t}+s S M B_{t}+h H M L_{t}+c R_{p, t-1}+\sum_{T=1}^{3} p_{T} V W P D_{t-T}+\varepsilon_{p, t}
\end{aligned}
$$


where:

$\mathrm{R}_{\mathrm{p}, \mathrm{t}}$ is the excess return of the two extreme decile portfolios: Decile 1 (small-size or low BVE/MVE stocks), and decile 10 (big-size or high BVE/MVE stocks);

$\mathrm{R}_{\mathrm{p}, \mathrm{t}-\mathrm{1}}$ is portfolio return lagged one month and is included in the models in order to control for serial correlation in the dependent variable;

VWPD $_{\mathrm{t}-\mathrm{T}}$ is the value-weighted PD lagged $\mathrm{T}$ months, letting $\mathrm{T}$ denote our forecasting horizon ( $\mathrm{T}=1,2$, or 3 months).

The testable hypothesis which relates to the above predictive regression models states that if high investor sentiment forecasts low stock returns in subsequent periods, then $p_{T}$, the coefficient of $\mathrm{VWPD}_{\mathrm{t}-\mathrm{T}}$ is expected to be significant and to have a negative sign.

Finally, we followed Baker and Wurgler (2006) and examined whether VWPD is able to predict the size and the BVE/MVE premiums. We estimated the size premium as the differential return between the two extreme size-sorted decile portfolios (small-size minus big-size portfolio returns) and the BVE/MVE premium as the differential return between the two extreme BVE/MVE-sorted decile portfolios (high-BVE/MVE minus lowBVE/MVE portfolio returns). The size and the BVE/MVE premiums correspond to the returns of two equallyweighted hedge portfolios which are long on small-size or high-BVE/MVE stocks and short on big-size or lowBVE/MVE stocks respectively.

To answer the question as to whether VWPD is able to predict the returns of the two hedge portfolios we ran the following regressions:

$$
\begin{aligned}
& R_{H, t}=a+c R_{H, t-1}+p V W P D_{t-1}+\varepsilon_{H, t} \\
& R_{H, t}=a+\beta R_{M, t}+s S M B_{t}+h H M L_{t}+c R_{H, t-1}+p V W P D_{t-1}+\varepsilon_{H, t}
\end{aligned}
$$

where $\mathrm{R}_{\mathrm{H}, \mathrm{t}}$ is the return of the hedge portfolio and the rest of the variables are as previously defined. The two FamaFrench factors were included in the predictive regressions in order to distinguish between predictability and comovement effects. Moreover, since our portfolios are equally weighted, controlling for SMB makes it possible to examine whether conditional predictability is independent of size.

The testable hypothesis which relates to our last two regression models states that if the two premiums are at high levels when investor sentiment is high, then VWPD should be able to forecast the returns of the long-short portfolios which proxy for the respective premiums (Baker and Wurgler, 2006).

\section{EMPIRICAL RESULTS}

\section{Basic Results}

Theoretical predictions and empirical evidence suggest that investor sentiment boosts to high levels in hotmarket periods. The market burst of the summer of year 1999 prevails as the most characteristic example and many studies have reported that during this period several perceived proxies for small investor sentiment peaked at extremely high levels (i.e., Baker and Wurgler, 2006 and 2007).

Unsurprisingly, our primary findings document similar patterns. Figure 1 portrays the monthly evolution of the ASE-CPI and of the VWPD respectively over the sample period, from 1/31/1997 to 12/31/2007. Looking at Figure 1 we observe that our period of investigation can be broken into three sub-periods with respect to the behavior of the market: a bullish market period from 1997 to 1999, a bearish market period from 2000 to 2003 and a second bullish market period from 2004 to 2007. 


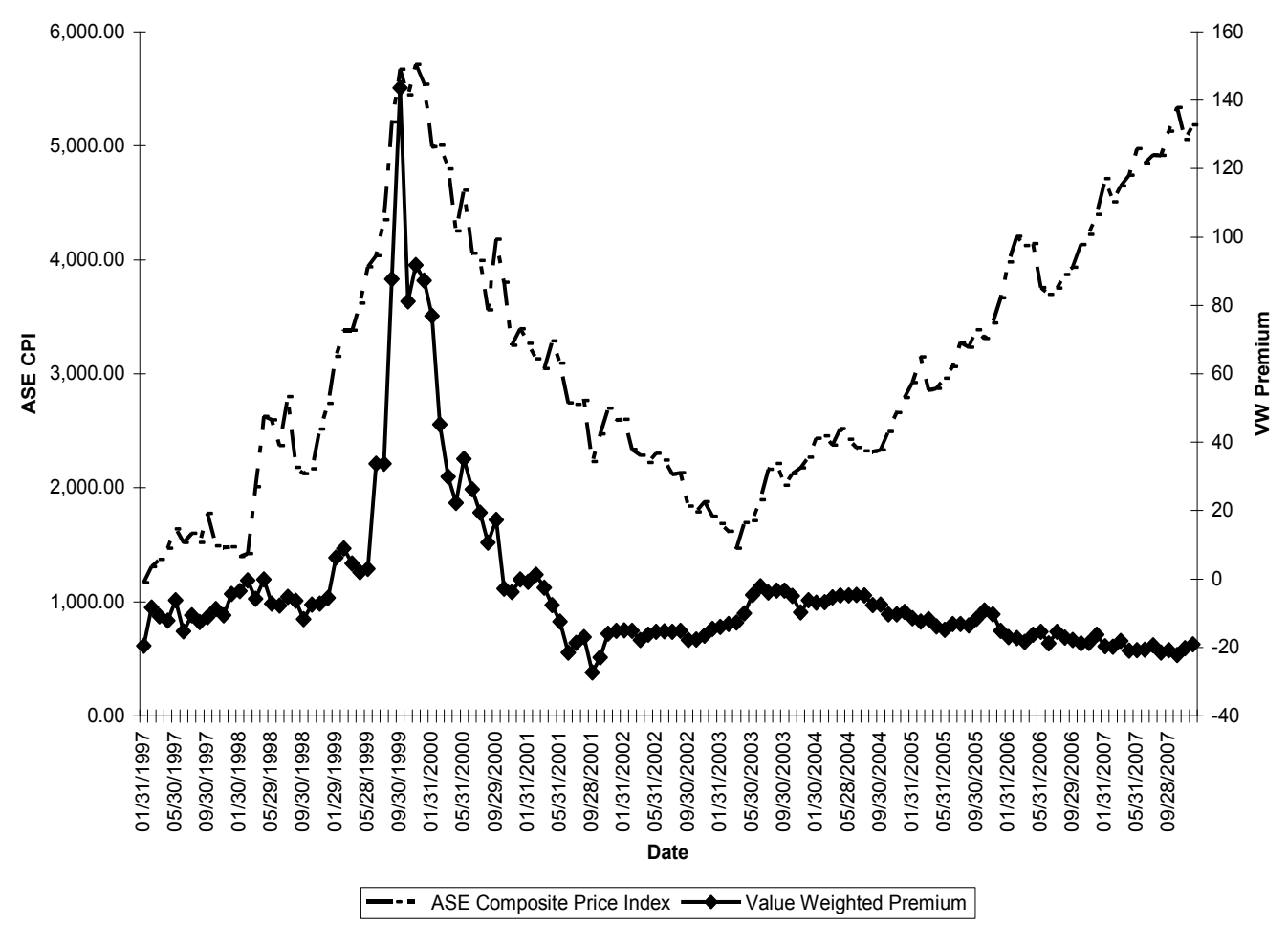

Figure 1: The Monthly Evolution Of The Premium (Discount) Of Greek Closed-End Funds

Figure 1 also shows that VWPD exhibited a similar trend to that of the market during the bullish period of 1999 and during the depression period which followed. During the second bullish period of the market, VWPD appears to be unable to explain the trend of the market. In particular, VWPD displayed a slight increasing trend around year 2004 which however shortly reversed to a decreasing trend that lasted until the end of year 2007. Nevertheless, this latter increase, although slight and short, was likely associated with the outcome of two important sports events which potentially uplifted investor mood and sentiment (i.e., Edmans et al., 2007). In particular, in year 2004 Greece won for the first time in history the European Football Championship and successfully hosted the Olympic Games. This explanation, however, is merely speculation and requires additional investigation.

To further explore the dynamics of the VWPD within the context of the investor sentiment model we examined whether Greek CEFs exhibit the same puzzling behavior as their US counterparts. For example, Lee et al. (1990, pp. 154-5) identify four main pricing puzzles associated with the PD of CEFs:

1. New funds appear on the market at a premium and move rapidly to a discount.

2. Closed-end funds usually trade at substantial discounts relative to their net asset values.

3. Discounts and premia are subject to wide variation, both over time and across funds.

4. When CEFs are terminated, either through merger, liquidation, or conversion to an open=end fund, prices converge to reported net asset value. 
Table 2: Portfolio Returns Summary Statistics Panel A: Portfolios Sorted By Size

\begin{tabular}{|c|c|c|c|c|c|c|c|c|c|}
\hline \multicolumn{10}{|c|}{ Panel A: Portfolios Sorted By Size } \\
\hline & \multicolumn{3}{|c|}{ Negative Sentiment Period } & \multicolumn{3}{|c|}{ Positive Sentiment Period } & \multicolumn{3}{|c|}{ Entire Period } \\
\hline & Mean & Std. Dev. & CV & Mean & Std. Dev. & CV & Mean & Std. Dev. & CV \\
\hline S1 (Small Size) & $-2.93 \%$ & $12.84 \%$ & -0.228 & $4.94 \%$ & $41.12 \%$ & 0.120 & $-1.68 \%$ & $20.12 \%$ & -0.083 \\
\hline $\mathrm{S} 2$ & $-1.27 \%$ & $12.32 \%$ & -0.103 & $15.14 \%$ & $54.37 \%$ & 0.279 & $1.34 \%$ & $24.80 \%$ & 0.054 \\
\hline S3 & $0.17 \%$ & $11.58 \%$ & 0.015 & $14.37 \%$ & $49.93 \%$ & 0.288 & $2.43 \%$ & $22.81 \%$ & 0.106 \\
\hline S4 & $0.06 \%$ & $10.69 \%$ & 0.006 & $19.12 \%$ & $58.68 \%$ & 0.326 & $3.09 \%$ & $25.90 \%$ & 0.119 \\
\hline S5 & $0.87 \%$ & $9.68 \%$ & 0.090 & $19.23 \%$ & $60.07 \%$ & 0.320 & $3.79 \%$ & $25.98 \%$ & 0.146 \\
\hline S6 & $0.48 \%$ & $10.40 \%$ & 0.046 & $16.37 \%$ & $61.44 \%$ & 0.267 & $3.01 \%$ & $26.48 \%$ & 0.114 \\
\hline S7 & $1.66 \%$ & $9.55 \%$ & 0.174 & $17.21 \%$ & $61.19 \%$ & 0.281 & $4.14 \%$ & $26.09 \%$ & 0.159 \\
\hline S8 & $2.33 \%$ & $9.93 \%$ & 0.235 & $14.36 \%$ & $55.91 \%$ & 0.257 & $4.24 \%$ & $24.07 \%$ & 0.176 \\
\hline S9 & $2.38 \%$ & $9.84 \%$ & 0.241 & $16.33 \%$ & $56.14 \%$ & 0.291 & $4.60 \%$ & $24.26 \%$ & 0.189 \\
\hline S10 (Big Size) & $2.49 \%$ & $9.03 \%$ & 0.276 & $14.78 \%$ & $51.76 \%$ & 0.286 & $4.44 \%$ & $22.32 \%$ & 0.199 \\
\hline
\end{tabular}

\begin{tabular}{|c|c|c|c|c|c|c|c|c|c|}
\hline \multicolumn{10}{|c|}{ Panel B: Portfolios Sorted By BVE/MVE Ratio } \\
\hline & \multicolumn{3}{|c|}{ Negative Sentiment Period } & \multicolumn{3}{|c|}{ Positive Sentiment Period } & \multicolumn{3}{|c|}{ Entire Period } \\
\hline & Mean & Std. Dev. & CV & Mean & Std. Dev. & CV & Mean & Std. Dev. & CV \\
\hline BM1 (Low BVE/MVE) & $3.13 \%$ & $9.25 \%$ & 0.338 & $19.12 \%$ & $53.53 \%$ & 0.357 & $5.67 \%$ & $23.32 \%$ & 0.243 \\
\hline BM2 & $2.61 \%$ & $8.86 \%$ & 0.294 & $17.18 \%$ & $49.07 \%$ & 0.350 & $4.93 \%$ & $21.50 \%$ & 0.229 \\
\hline BM3 & $1.64 \%$ & $9.34 \%$ & 0.175 & $15.86 \%$ & $50.64 \%$ & 0.313 & $3.90 \%$ & $22.18 \%$ & 0.176 \\
\hline BM4 & $1.56 \%$ & $9.72 \%$ & 0.161 & $17.90 \%$ & $63.68 \%$ & 0.281 & $4.16 \%$ & $27.10 \%$ & 0.154 \\
\hline BM5 & $0.64 \%$ & $10.15 \%$ & 0.063 & $16.26 \%$ & $59.89 \%$ & 0.272 & $3.13 \%$ & $25.83 \%$ & 0.121 \\
\hline BM6 & $0.61 \%$ & $10.51 \%$ & 0.058 & $15.87 \%$ & $57.70 \%$ & 0.275 & $3.03 \%$ & $25.15 \%$ & 0.121 \\
\hline BM7 & $0.45 \%$ & $10.69 \%$ & 0.042 & $13.29 \%$ & $54.42 \%$ & 0.244 & $2.50 \%$ & $23.88 \%$ & 0.105 \\
\hline BM8 & $-0.51 \%$ & $11.48 \%$ & -0.044 & $17.17 \%$ & $63.27 \%$ & 0.271 & $2.30 \%$ & $27.64 \%$ & 0.083 \\
\hline BM9 & $-1.59 \%$ & $11.18 \%$ & -0.142 & $12.73 \%$ & $48.19 \%$ & 0.264 & $0.69 \%$ & $22.07 \%$ & 0.031 \\
\hline BM10 (High BVE/MVE) & $-3.01 \%$ & $12.90 \%$ & -0.234 & $6.93 \%$ & $47.55 \%$ & 0.146 & $-1.43 \%$ & $22.32 \%$ & -0.064 \\
\hline
\end{tabular}

Notes: Positive (negative) sentiment period refers to the months in which the VWPD is positive (negative). The positive sentiment period covers 22 months while the negative sentiment period covers 110 months. Decile portfolio returns are estimated on an equally-weighted basis. CV is the coefficient of variation calculated as the mean divided by the standard deviation and reflects portfolio return per unit of risk. 
We begun our analysis by looking at Figure 1 which reveals that for most of the time period examined Greek CEFs traded at a discount. VWPD was found to be positive in only 22 out of the 132 months of the sample period, from January 1999 to September 2000, and in February 2001. We term the period in which VWPD was positive as our positive sentiment period and the period in which VWPD was negative as our negative sentiment period.

We then examined the cross-sectional variation in our style-portfolio returns and the standard deviation within these two periods and within the entire sample period. These results are exhibited in Table 2 and show that portfolio returns were higher in periods of positive sentiment than in periods of negative sentiment. Moreover, the results indicate that irrespective of the time period examined, portfolio returns exhibited a pattern associated with their style: on average, bigger size and lower BVE/MVE firms delivered higher returns than smaller size and higher BVE/MVE firms respectively. This result, which explains the negative signs of the SMB and HML factors, is also justified by the coefficient of variation (CV) which controls for portfolio risk-return trade-off. The implication of this finding is that investors in Greece prefer placing their investments in stocks of large capitalization and low BVE/MVE (growth) firms. A likely explanation could be that the majority of the volume of transactions in the ASE is conducted by institutional investors, especially banking and insurance firms which face portfolio-risk restrictions.

In terms of IPO performance, the majority of the U.S. evidence advocates that on average, new CEFs are issued at a premium which in some later period reverts to a discount. Nevertheless, there appears to be some disagreement on the time it takes for a newly issued fund to fall to a discount. Lee et al. (1990) reviewed several early studies in the area which reported that the rate of reversion to a discount is very short (as short as 120 days). Hence, they seemed to be puzzled about the reasons why any rational investor would buy shares of CEFs when they are first issued. More recent evidence however, reported a considerably longer average time of reversion to a discount and asserted that the post-IPO performance of CEFs resembles that of industrial IPOs. For example, Berk and Stanton (2007) and Cherkes et al. (2009) supported that the time it takes for a new fund to turn from a premium to a discount is approximately two years.

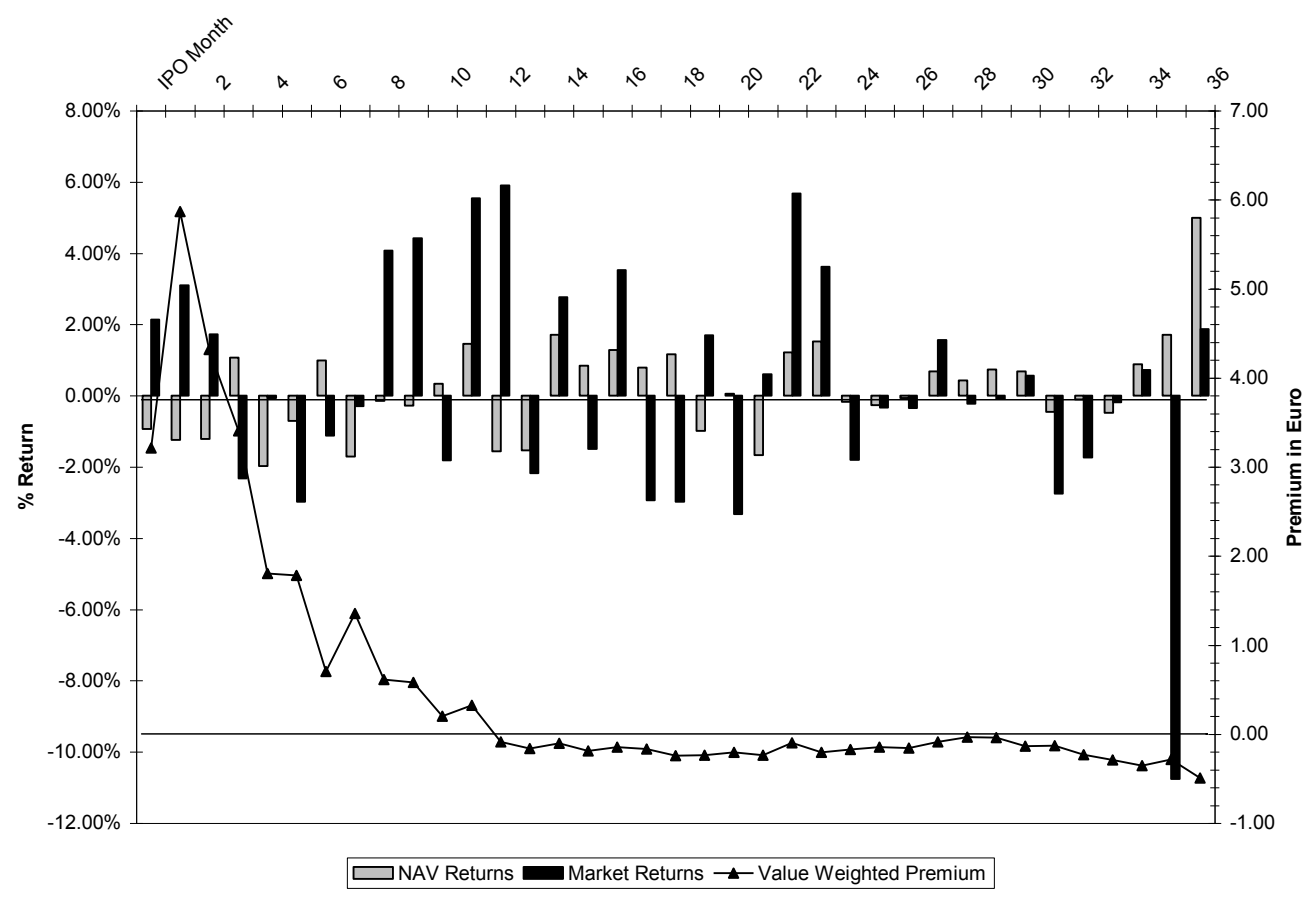

Figure 2: The Monthly Evolution Of The Average Premium (Discount) Of Newly-Issued CEFs Over The 36-Month Period Following The IPO Month 
Within our sample period we identified 15 Greek CEF IPOs. For each newly issued CEF we estimated the PD and the NAV and market returns over a period of 36 months following the IPO month. We then averaged out these variables across firms and estimated the value-weighted average PD and the value-weighted average NAV and market returns of new CEFs over the 36-month period following the IPO month. These results are graphically presented in Figure 2 and suggest that new CEFs traded at a premium for a period of approximately 12 months and afterwards reverted to a discount. This rate of reversion to a discount seems to better conform to the recent evidence of Berk and Stanton (2007) and of Cherkes et al. (2009) rather than to the behavioral model of Lee et al. (1990, 1991). Moreover, because the number of CEF IPOs was scattered unevenly throughout the sample period and clustered within the period $1998-2004$ we also drew the pattern of NAV and market returns. These results are shown in the upper part of Figure 2. It appears that average market returns exceeded average NAV returns for a period of about 24 months and fell short of NAV returns in the period that followed. Clearly this result indicates that the post-IPO performance of Greek CEFs does not exhibit any empirical irregularities and shares many commonalities with the performance of industrial IPOs in Greece (Papaioannou et al., 1997).

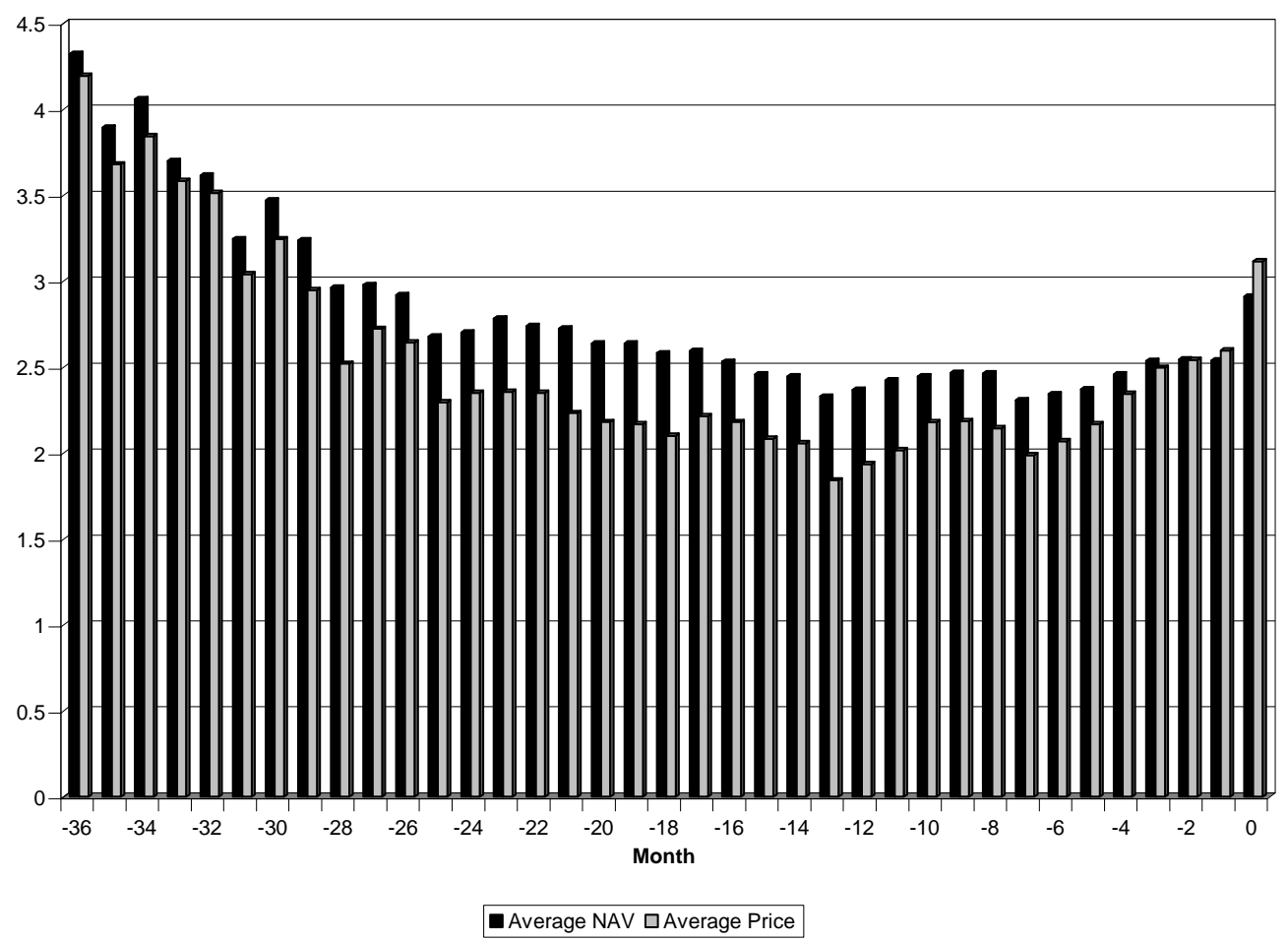

Figure 3: The Monthly Evolution Of NAV And Market Prices Of Non-Surviving Greek CEFs Over A Period Of 36 Months Prior To Termination Month (Month 0 On The Horizontal Axis)

In a final illustration, we examined the behavior of the prices of CEFs around termination. Lee et al. (1990) argue that when a CEF is terminated its assets are redeemed at the NAV, so market prices at termination should converge to the NAV. The only deviation allowed from this theoretical prediction is when NAVs are mismeasured. In this case, it is NAVs that should converge to market prices rather than vice versa. Therefore, the fact that around termination the market prices of CEFs converge to their respective NAVs is a strong indication that the PD of CEFs consists of a clear pricing anomaly (divergence from the fundamental values) rather than a NAV miscalculation effect.

We used NAV and market price data for a number of 22 Greek CEFs which were terminated within our sample period either through merger, liquidation or conversion to an open-end fund. The data were averaged out 
across non-surviving CEFs over a period of 36 months prior to termination. Figure 3 presents these data which draw the monthly evolution of the value weighted average NAV and market price of non-surviving CEFs for a period of 36 months prior to the month of termination (denoted as month 0 on the horizontal axis). The results revealed an interesting pattern. On average terminating CEFs traded at market prices which are lower than the respective NAVs throughout the 36-month period. Over a period of approximately 10 months prior to termination market prices begun to exhibit a tendency of convergence to the net asset values. Market prices eventually converged to the NAVs 3 months prior to CEF termination implying the predictions of the investor sentiment model, namely that the PD of CEFs is unlikely to be owed to NAV miscalculation.

\section{Contemporaneous Regression Results}

In light of our preliminary results, we turned our investigation to the importance of the PD of Greek CEFs as a proxy of sentiment risk in a purely valuation framework. Our first step in examining the significance of investor sentiment in asset valuations was to include VWPD in an asset pricing model like the CAPM, which regresses portfolio returns on market index returns. Table 3 exhibits the results of regressing size and BVE/MVE sorted portfolio excess returns on the excess return of the market and on the VWPD. Under the tested hypothesis that investor sentiment drives stock prices above fundamentals, the slope coefficient $p$ should be positive and significant. Under the null hypothesis that investor sentiment does not affect asset valuations, VWPD should not enter the regressions significantly.

Panel A of Table 3 tabulates regression results for portfolios sorted by size. It turns out that our results are somewhat complicated. Contrary to the behavioral view that investor sentiment affects mainly small-size stocks, our results show VWPD to be significant as an explanatory variable for the returns of large-size stock portfolios. In particular, the effect of VWPD was found to be insignificant for decile portfolios S1 (small size stocks), S2 and S3 and significant (at various significance levels) for the remaining decile portfolios. Especially in the case of decile portfolio S10 (big size stocks), VWPD was found to be significant at the 1 percent level. Moreover, like Brown and Cliff (2005), we found that the value of the slope coefficient $p$ is higher for portfolio S10, implying that big-size stocks in Greece are the most exposed to sentiment risk.

In Panel B of Table 3 we turn our regression analysis to portfolios sorted by the BVE/MVE ratio. The reported results are again complicated but this time they appear to conform better to the behavioral view which states that low BVE/MVE (growth) stocks are most affected by sentiment risk because their subjective valuations make them relatively hard to arbitrage.

By looking at the results of Panel B we observe that although VWPD explains with some degree of consistency cross sectional variations in risk and returns of BVE/MVE-sorted portfolios it does not enter all regressions significantly. VWPD was found to be significant (at various significance levels) in explaining the returns of seven of the BVE/MVE decile portfolios. Nevertheless, the $p$ slope coefficient was found to be significant at the 1 percent level for the two decile portfolios which included the lowest BVE/MVE firms. Moreover, the values of the $p$ coefficient were higher for these two portfolios than for the remaining portfolios, implying that sentiment risk is higher for portfolios of low BVE/MVE stocks. Consistently, the $p$ slope coefficient exhibited its lowest value in the case of the high BVE/MVE portfolio, but it was not significant even at the 10 percent level.

Turning to fundamental analysis, the results of both Panels A and B of Table 3 reveal that the pattern of the $\beta$ slope coefficients complies with theoretical predictions. In all regressions the $\beta$ slope was found significant at the 1 percent level and its value was higher for small size and high BVE/MVE stocks than for big size and low BVE/MVE stocks. However, despite its theoretical appeal this result is inconsistent with the cross-section of average portfolio returns reported in Panels A and B of Table 2.

Overall the results reported thus far suggest that big size and low BVE/MVE stocks display lower systematic risk than small size and high BVE/MVE stocks and deliver higher returns. At this point we are unable to offer a sound fundamental explanation for these results. The likely explanation that the reported correlations reflect investment preferences of Greek CEFs appears unable to support the inverse relation between systematic risk and portfolio returns. Therefore we turn our attention to a behavioral explanation for these results. This explanation 
builds on the fact that both big size and low BVE/MVE stocks are found to be more exposed to sentiment risk than small size and high BVE/MVE stocks. Hence, the excess returns that they deliver are likely to consist of a compensation for their increased sentiment risk, implying that VWPD is an adequate proxy for sentiment risk which in turn needs to be priced.

Table 3: The Significance of VWPD in Univariate Regressions

$$
R_{p, t}=a+\beta R_{M, t}+p V W P D_{t}+e_{p, t}
$$

\begin{tabular}{|c|c|c|c|c|c|c|}
\hline \multicolumn{7}{|c|}{ Panel A: Portfolios Sorted by Size } \\
\hline & tfolios & & $\alpha$ & $\boldsymbol{\beta}$ & $p$ & $\operatorname{Adj} . R^{2}$ \\
\hline \multirow{3}{*}{ S1 } & \multirow{3}{*}{ (Small Size) } & Coefficient & -0.034 & $1.037 *$ & 0.013 & \multirow{3}{*}{0.199} \\
\hline & & t-statistic & -2.120 & 4.838 & 0.203 & \\
\hline & & p-value & 0.036 & 0.000 & 0.839 & \\
\hline \multirow{3}{*}{\multicolumn{2}{|c|}{$\mathbf{S 2}$}} & Coefficient & -0.001 & $1.113 *$ & 0.104 & \multirow{3}{*}{0.163} \\
\hline & & t-statistic & -0.057 & 5.356 & 1.398 & \\
\hline & & p-value & 0.955 & 0.000 & 0.165 & \\
\hline \multirow{3}{*}{\multicolumn{2}{|c|}{ S3 }} & Coefficient & 0.010 & $1.068 *$ & 0.084 & \multirow{3}{*}{0.174} \\
\hline & & t-statistic & 0.541 & 5.575 & 1.202 & \\
\hline & & p-value & 0.590 & 0.000 & 0.232 & \\
\hline \multirow{3}{*}{\multicolumn{2}{|c|}{ S4 }} & Coefficient & 0.018 & $1.064 *$ & $0.138^{* *}$ & \multirow{3}{*}{0.145} \\
\hline & & t-statistic & 0.907 & 4.855 & 2.246 & \\
\hline & & p-value & 0.366 & 0.000 & 0.026 & \\
\hline \multirow{3}{*}{\multicolumn{2}{|c|}{ S5 }} & Coefficient & 0.026 & 0.994* & $0.141^{*}$ & \multirow{3}{*}{0.127} \\
\hline & & t-statistic & 1.290 & 4.865 & 2.742 & \\
\hline & & p-value & 0.200 & 0.000 & 0.007 & \\
\hline \multirow{3}{*}{\multicolumn{2}{|c|}{ S6 }} & Coefficient & 0.017 & $1.023^{*}$ & $0.114^{* *}$ & \multirow{3}{*}{0.121} \\
\hline & & t-statistic & 0.820 & 5.032 & 2.303 & \\
\hline & & p-value & 0.414 & 0.000 & 0.023 & \\
\hline \multirow{3}{*}{\multicolumn{2}{|c|}{ S7 }} & Coefficient & 0.028 & $0.965 *$ & $0.091 * * *$ & \multirow{3}{*}{0.106} \\
\hline & & t-statistic & 1.281 & 4.311 & 1.718 & \\
\hline & & p-value & 0.202 & 0.000 & 0.088 & \\
\hline \multirow{3}{*}{\multicolumn{2}{|c|}{ S8 }} & Coefficient & 0.027 & $1.082 *$ & $0.067 * * *$ & \multirow{3}{*}{0.155} \\
\hline & & t-statistic & 1.479 & 5.006 & 1.906 & \\
\hline & & p-value & 0.142 & 0.000 & 0.059 & \\
\hline \multirow{3}{*}{\multicolumn{2}{|c|}{ S9 }} & Coefficient & 0.032 & $1.089 *$ & $0.108 * *$ & \multirow{3}{*}{0.165} \\
\hline & & t-statistic & 1.681 & 4.504 & 2.147 & \\
\hline & & p-value & 0.095 & 0.000 & 0.034 & \\
\hline \multirow{3}{*}{ S10 } & \multirow{3}{*}{ (Big Size) } & Coefficient & 0.032 & $0.954 *$ & $0.100^{*}$ & \multirow{3}{*}{0.150} \\
\hline & & t-statistic & 1.828 & 7.073 & 4.168 & \\
\hline & & p-value & 0.070 & 0.000 & 0.000 & \\
\hline
\end{tabular}


Table 3 (Continued): The Significance Of VWPD In Univariate Regressions

$$
R_{p, t}=a+\beta R_{M, t}+p V W P D_{t}+e_{p, t}
$$

\begin{tabular}{|c|c|c|c|c|c|}
\hline \multicolumn{6}{|c|}{ Panel B: Portfolios Sorted by BVE/MVE Ratio } \\
\hline Portfolios & & $\alpha$ & $\boldsymbol{\beta}$ & $p$ & $\operatorname{Adj} . R^{2}$ \\
\hline \multirow{3}{*}{$\begin{array}{c}\text { BM1 } \\
\text { (Low BVE/MVE) }\end{array}$} & Coefficient & 0.045 & $0.935^{*}$ & $0.139 *$ & \multirow{3}{*}{0.144} \\
\hline & t-statistic & 2.502 & 5.847 & 2.656 & \\
\hline & p-value & 0.014 & 0.000 & 0.009 & \\
\hline \multirow{3}{*}{ BM2 } & Coefficient & 0.039 & $0.952 *$ & $0.154 *$ & \multirow{3}{*}{0.185} \\
\hline & t-statistic & 2.304 & 6.668 & 3.013 & \\
\hline & p-value & 0.023 & 0.000 & 0.003 & \\
\hline \multirow{3}{*}{ BM3 } & Coefficient & 0.027 & $0.945^{*}$ & $0.111 * *$ & \multirow{3}{*}{0.153} \\
\hline & t-statistic & 1.552 & 5.626 & 2.112 & \\
\hline & p-value & 0.123 & 0.000 & 0.037 & \\
\hline \multirow{3}{*}{ BM4 } & Coefficient & 0.027 & $1.076^{*}$ & $0.094 * * *$ & \multirow{3}{*}{0.123} \\
\hline & t-statistic & 1.274 & 5.896 & 1.754 & \\
\hline & p-value & 0.205 & 0.000 & 0.082 & \\
\hline \multirow{3}{*}{ BM5 } & Coefficient & 0.018 & $1.034^{*}$ & 0.110 & \multirow{3}{*}{0.130} \\
\hline & t-statistic & 0.877 & 4.861 & 1.639 & \\
\hline & p-value & 0.382 & 0.000 & 0.104 & \\
\hline \multirow{3}{*}{ BM6 } & Coefficient & 0.017 & $1.074^{*}$ & $0.113 * *$ & \multirow{3}{*}{0.150} \\
\hline & t-statistic & 0.851 & 5.339 & 2.081 & \\
\hline & p-value & 0.396 & 0.000 & 0.039 & \\
\hline \multirow{3}{*}{ BM7 } & Coefficient & 0.009 & $1.052 *$ & 0.041 & \multirow{3}{*}{0.145} \\
\hline & t-statistic & 0.480 & 5.322 & 0.700 & \\
\hline & p-value & 0.632 & 0.000 & 0.485 & \\
\hline \multirow{3}{*}{ BM8 } & Coefficient & 0.008 & $1.115^{*}$ & $0.084 * * *$ & \multirow{3}{*}{0.125} \\
\hline & t-statistic & 0.328 & 3.937 & 1.741 & \\
\hline & p-value & 0.743 & 0.000 & 0.084 & \\
\hline \multirow{3}{*}{ BM9 } & Coefficient & -0.007 & $1.041^{*}$ & $0.105 * *$ & \multirow{3}{*}{0.184} \\
\hline & t-statistic & -0.508 & 4.610 & 2.138 & \\
\hline & p-value & 0.612 & 0.000 & 0.034 & \\
\hline \multirow{3}{*}{$\begin{array}{c}\text { BM10 } \\
\text { (High BVE/MVE) }\end{array}$} & Coefficient & -0.032 & $1.146^{*}$ & 0.022 & \multirow{3}{*}{0.199} \\
\hline & t-statistic & -1.890 & 5.797 & 0.451 & \\
\hline & p-value & 0.061 & 0.000 & 0.653 & \\
\hline
\end{tabular}

Notes: The results are based on monthly data from $31 / 1 / 1997$ to $31 / 12 / 2007$. $R_{p, t}$ is excess portfolio return; $R_{M, t}$ is excess market return of the ASE and $\mathrm{VWPD}_{\mathrm{t}}$ is the value weighted premium/discount of all listed Greek CEFs. When necessary, regression test statistics are based on standard errors corrected for conditional heteroscedasticity and autocorrelation of order $\mathrm{N}$ using the method in Newey and West (1987). The autoregressive lags are estimated by setting a maximum number of $\mathrm{N}=6$ and by choosing $\mathrm{N}$ which results in the minimum regression standard error. The superscripts $(*),(* *)$ and $(* * *)$ denote significance at the $1 \%, 5 \%$ and $10 \%$ levels respectively. 
Table 4: The Significance Of VWPD In Multivariate Regressions

$$
R_{p, t}=a+\beta R_{M, t}+s S M B_{t}+h H M L_{t}+p V W P D_{t}+u_{p, t}
$$

\begin{tabular}{|c|c|c|c|c|c|c|c|}
\hline \multicolumn{8}{|c|}{ Panel A: Portfolios Sorted by Size } \\
\hline Portfolios & & $\alpha$ & $\beta$ & $s$ & $\boldsymbol{h}$ & $p$ & $\operatorname{Adj.} R^{2}$ \\
\hline \multirow{3}{*}{$\begin{array}{c}\text { S1 } \\
\text { (Small Size) }\end{array}$} & Coefficient & -0.025 & $0.931 *$ & $1.572 *$ & -0.273 & -0.019 & \multirow{3}{*}{0.548} \\
\hline & t-statistic & -1.624 & 8.499 & 6.682 & -1.019 & -0.421 & \\
\hline & p-value & 0.107 & 0.000 & 0.000 & 0.310 & 0.674 & \\
\hline \multirow{3}{*}{$\mathbf{S 2}$} & Coefficient & 0.004 & $1.000 *$ & $1.708 *$ & -0.426 & 0.061 & \multirow{3}{*}{0.431} \\
\hline & t-statistic & 0.256 & 6.686 & 4.721 & -1.324 & 1.397 & \\
\hline & p-value & 0.799 & 0.000 & 0.000 & 0.188 & 0.165 & \\
\hline \multirow{3}{*}{$\mathbf{S 3}$} & Coefficient & 0.019 & $0.967 *$ & $1.489^{*}$ & -0.239 & 0.055 & \multirow{3}{*}{0.413} \\
\hline & t-statistic & 1.057 & 7.132 & 4.488 & -0.769 & 1.063 & \\
\hline & p-value & 0.292 & 0.000 & 0.000 & 0.443 & 0.290 & \\
\hline \multirow{3}{*}{$\mathbf{S 4}$} & Coefficient & 0.027 & $0.968 *$ & $1.414 *$ & -0.225 & 0.111 & \multirow{3}{*}{0.308} \\
\hline & t-statistic & 1.307 & 6.855 & 3.351 & -0.611 & 1.651 & \\
\hline & p-value & 0.194 & 0.000 & 0.001 & 0.542 & 0.101 & \\
\hline \multirow{3}{*}{ S5 } & Coefficient & 0.031 & $0.906^{*}$ & $1.322 *$ & -0.301 & $0.109 * *$ & \multirow{3}{*}{0.267} \\
\hline & t-statistic & 1.580 & 7.077 & 2.975 & -0.850 & 2.089 & \\
\hline & p-value & 0.117 & 0.000 & 0.004 & 0.397 & 0.039 & \\
\hline \multirow{3}{*}{ S6 } & Coefficient & 0.021 & $0.939 *$ & $1.265^{*}$ & -0.332 & $0.080 * *$ & \multirow{3}{*}{0.243} \\
\hline & t-statistic & 1.017 & 6.827 & 2.748 & -0.916 & 1.397 & \\
\hline & p-value & 0.311 & 0.000 & 0.007 & 0.361 & 0.165 & \\
\hline \multirow{3}{*}{ S7 } & Coefficient & 0.028 & $0.886^{*}$ & $1.207^{*}$ & -0.422 & $0.052 * *$ & \multirow{3}{*}{0.220} \\
\hline & t-statistic & 1.711 & 5.702 & 4.134 & -1.253 & 1.970 & \\
\hline & p-value & 0.089 & 0.000 & 0.000 & 0.213 & 0.051 & \\
\hline \multirow{3}{*}{ S8 } & Coefficient & 0.031 & $1.018 *$ & $0.969^{*}$ & -0.238 & $0.042 * * *$ & \multirow{3}{*}{0.238} \\
\hline & t-statistic & 1.724 & 6.496 & 4.786 & -0.934 & 1.774 & \\
\hline & p-value & 0.087 & 0.000 & 0.000 & 0.352 & 0.078 & \\
\hline \multirow{3}{*}{ S9 } & Coefficient & 0.033 & $1.033^{*}$ & $0.858 *$ & -0.265 & $0.082 *$ & \multirow{3}{*}{0.226} \\
\hline & t-statistic & 1.684 & 5.961 & 3.345 & -0.598 & 9.059 & \\
\hline & p-value & 0.095 & 0.000 & 0.001 & 0.551 & 0.000 & \\
\hline \multirow{3}{*}{$\begin{array}{c}\text { S10 } \\
\text { (Big Size) }\end{array}$} & Coefficient & 0.018 & $0.934^{*}$ & 0.413 & $-0.586 * * *$ & $0.056^{*}$ & \multirow{3}{*}{0.172} \\
\hline & t-statistic & 1.564 & 7.436 & 1.468 & -1.837 & 4.227 & \\
\hline & p-value & 0.120 & 0.000 & 0.139 & 0.068 & 0.000 & \\
\hline
\end{tabular}


Table 4 (Continued): The Significance Of VWPD In Multivariate Regressions

$$
R_{p, t}=a+\beta R_{M, t}+s S M B_{t}+h H M L_{t}+p V W P D_{t}+u_{p, t}
$$

\begin{tabular}{|c|c|c|c|c|c|c|c|}
\hline \multicolumn{8}{|c|}{ Panel B: Portfolios Sorted by BVE/MVE Ratio } \\
\hline Portfolios & & $\alpha$ & $\beta$ & $s$ & $\boldsymbol{h}$ & $p$ & $\operatorname{Adj} . R^{2}$ \\
\hline \multirow{3}{*}{$\begin{array}{c}\text { BM1 } \\
\text { (Low BVE/MVE) }\end{array}$} & Coefficient & 0.030 & $0.885^{*}$ & $0.890^{*}$ & $-0.811 * *$ & $0.076 * *$ & \multirow{3}{*}{0.240} \\
\hline & t-statistic & 4.381 & 7.874 & 3.007 & -2.028 & 2.060 & \\
\hline & p-value & 0.000 & 0.000 & 0.003 & 0.045 & 0.041 & \\
\hline \multirow{3}{*}{ BM2 } & Coefficient & 0.027 & $0.895^{*}$ & $0.957 *$ & $-0.702 *$ & $0.097 * *$ & \multirow{3}{*}{0.307} \\
\hline & t-statistic & 1.693 & 6.709 & 4.169 & -2.696 & 2.278 & \\
\hline & p-value & 0.093 & 0.000 & 0.000 & 0.008 & 0.024 & \\
\hline \multirow{3}{*}{ BM3 } & Coefficient & 0.021 & $0.876^{*}$ & $1.103 *$ & $-0.576^{* *}$ & $0.062 * *$ & \multirow{3}{*}{0.294} \\
\hline & t-statistic & 1.641 & 6.628 & 5.229 & -2.139 & 2.434 & \\
\hline & p-value & 0.103 & 0.000 & 0.000 & 0.034 & 0.016 & \\
\hline \multirow{3}{*}{ BM4 } & Coefficient & 0.021 & 0.996* & $1.276^{*}$ & $-0.650 * * *$ & 0.039 & \multirow{3}{*}{0.247} \\
\hline & t-statistic & 1.031 & 7.255 & 2.729 & -1.783 & 0.787 & \\
\hline & p-value & 0.305 & 0.000 & 0.007 & 0.077 & 0.433 & \\
\hline \multirow{3}{*}{ BM5 } & Coefficient & 0.015 & $0.952 *$ & $1.283^{*}$ & -0.546 & 0.061 & \multirow{3}{*}{0.266} \\
\hline & t-statistic & 0.718 & 7.159 & 2.936 & -1.451 & 0.867 & \\
\hline & p-value & 0.474 & 0.000 & 0.004 & 0.149 & 0.388 & \\
\hline \multirow{3}{*}{ BM6 } & Coefficient & 0.020 & $0.990 *$ & $1.271^{*}$ & -0.333 & 0.080 & \multirow{3}{*}{0.288} \\
\hline & t-statistic & 0.997 & 7.920 & 3.067 & -0.921 & 1.151 & \\
\hline & p-value & 0.321 & 0.000 & 0.003 & 0.359 & 0.252 & \\
\hline \multirow{3}{*}{ BM7 } & Coefficient & 0.018 & $0.967 *$ & $1.244^{*}$ & -0.153 & 0.020 & \multirow{3}{*}{0.292} \\
\hline & t-statistic & 0.993 & 8.010 & 3.157 & -0.468 & 0.387 & \\
\hline & p-value & 0.322 & 0.000 & 0.002 & 0.640 & 0.699 & \\
\hline \multirow{3}{*}{ BM8 } & Coefficient & 0.021 & $1.010 *$ & $1.527 *$ & -0.104 & $0.064 * * *$ & \multirow{3}{*}{0.292} \\
\hline & t-statistic & 1.177 & 6.594 & 4.585 & -0.259 & 1.923 & \\
\hline & p-value & 0.242 & 0.000 & 0.000 & 0.796 & 0.057 & \\
\hline \multirow{3}{*}{ BM9 } & Coefficient & 0.013 & $0.957 *$ & $1.167 *$ & 0.206 & $0.110^{*}$ & \multirow{3}{*}{0.348} \\
\hline & t-statistic & 0.807 & 7.136 & 5.931 & 0.564 & 3.357 & \\
\hline & p-value & 0.421 & 0.000 & 0.000 & 0.574 & 0.001 & \\
\hline \multirow{3}{*}{$\begin{array}{c}\text { BM10 } \\
(\text { High BVE/MVE) }\end{array}$} & Coefficient & -0.011 & $1.050 *$ & $1.340^{*}$ & 0.209 & 0.026 & \multirow{3}{*}{0.411} \\
\hline & t-statistic & -2.022 & 10.760 & 8.122 & 0.696 & 0.866 & \\
\hline & p-value & 0.045 & 0.000 & 0.000 & 0.488 & 0.388 & \\
\hline
\end{tabular}

Notes: The results are based on monthly data from 31/1/1997 to 31/12/2007. $\mathrm{R}_{\mathrm{p}, \mathrm{t}}$ is excess portfolio return; $\mathrm{R}_{\mathrm{M}, \mathrm{t}}$ is excess market return of the ASE; SMB and HML are the Fama-French mimicking risk factors and $\mathrm{VWPD}_{\mathrm{t}}$ is the value weighted premium/discount of all listed Greek CEFs. When necessary, regression test statistics are based on standard errors corrected for conditional heteroscedasticity and autocorrelation of order $\mathrm{N}$ using the method in Newey and West (1987). The autoregressive lags were estimated by setting a maximum number of $\mathrm{N}=6$ and by choosing $\mathrm{N}$ which results in the minimum regression standard error. The superscripts $(*),(* *)$ and $(* * *)$ denote significance at the $1 \%, 5 \%$ and $10 \%$ levels respectively. 
A question that we address in Table 4 is whether the above results persist even when the asset pricing model is augmented by the mimicking risk factors of Fama and French $(1992,1993)$. Panels A and B of Table 4 report regression results for the size and BVE/MVE sorted portfolios respectively. Clearly, the value of the $p$ slope coefficient diminished in all cases. However, it still remained significant, at least at the 5 percent level, in explaining the returns of big size and low BVE/MVE stocks and still revealed that big size and low BVE/MVE stocks are more risky than small size and high BVE/MVE stocks respectively.

On the other hand, the $\beta$ and the $s$ slope coefficients were found to be significant at the 1 percent level in almost all of the cases. However, it is the $h$ slope coefficient which displays a quite interesting performance. First, it prevailed with a negative sign in the majority of the cases implying that HML is inversely related to portfolio returns. Second, it was found to be significant, at least at the 10 percent level, in explaining the returns of big size and low BVE/MVE portfolio returns. Finally, unlike the $\beta$ and the $s$ slopes, when taken in absolute terms it reveals that big size and low BVE/MVE stocks are more risky than small size and high BVE/MVE stocks respectively.

On average, the performance of the $h$ slope coefficient shares many commonalities with that of the $p$ slope coefficient. Therefore, on the assumption that the book-to-market ratio helps to reveal investor overreaction in good and bad market times (i.e., DeBondt and Thaler, 1987; Lakonishok et al., 1994), the results of Table 4 confirm that the cross-section of portfolio returns is conditional on sentiment in the observed manner, namely that big size and low BVE/MVE stocks are more exposed to investor sentiment and deliver higher returns to compensate for the underlying sentiment risk. However, our results also confirm that even when investor overreaction violates rational market pricing, the HML factor portfolio exposes the incremental risk for which investors require compensation. Moreover, in a purely Fama-French regression framework ${ }^{5}$, the HML factor enters the regressions significantly in explaining the observed risk-return trade off of big versus small size portfolios and of low versus high BVE/MVE portfolios. Therefore, the conclusion that we draw from our findings states that even when investor sentiment induces mispricing in the market, VWPD exhibits little incremental information content over the HML risk factor in explaining cross-sectional variations in portfolio returns.

\section{Predictive Regression Results}

Another way to look for the significance of VWPD as a measure of investor sentiment is to examine its ability to forecast near-term reversal in portfolio returns. In particular, our hypothesized pattern of portfolio returns predicts that periods of high sentiment are followed by periods of low portfolio returns. Moreover, our findings thus far suggest that sentiment affects mainly big-size and low BVE/MVE stocks and therefore, we expect to see reversal at least in the returns of the decile portfolios including these stocks.

Table 5 tabulates the results of using lagged values of the VWPD to forecast portfolio returns over the next three-month period. While Neal and Wheatley (1998) and Brown and Cliff $(2004,2005)$ tested for the predictive ability of sentiment over both short and long term horizons, we followed Brown and Cliff (2004) and Baker and Wurgler (2006) and chose a short term forecasting horizon because our interest lay with short term reversals in portfolio returns. The results of Table 5 appear to justify our choice and report that VWPD lagged three months entered significantly in both our predictive regression models with a negative sign. Of course, when moving from Model 1 to Model 2 the absolute value of its coefficient decreases and its significance drops to lower levels, but it still remains significant at least at the 10 percent level.

On the other hand, VWPD lagged one or two months exhibited predictive inconsistency in both direction and magnitude. VWPD lagged one month was negative but insignificant in predicting the returns of big size and low BVE/MVE portfolios while VWPD lagged two months was positive and insignificant in the case of all four portfolios.

Arguably, it is difficult to explain why only VWPD lagged three months displayed some degree of predictive ability for the reversal in portfolio returns. However, the fact that VWPD lagged one or two months was unable to significantly predict this reversal lends support to Brown and Cliff (2004) who showed that measures of sentiment exhibit no predictive power for stock returns in the short run. Since our results produce mixed evidence on return predictability, we performed a standard likelihood ratio test (LRT) to see whether we had significant evidence to 
reject the form of our predictive models, or equivalently, to reject the null hypothesis that sentiment exhibits the ability to forecast near-term return reversals. Unfortunately, the values of the LRT statistic for all eight predictive regressions ranged from 0.637 to 3.297 and were not found to be significant even at the 10 percent level. The implication is that our predictive regression models were not well specified and hence the hypothesis that VWPD exhibits predictive power for portfolio returns was rejected.

Table 5: The Significance Of VWPD In Predictive Regressions

Model 1: $R_{p, t}=a+c R_{p, t-1}+\sum_{T=1}^{3} p_{T} V W P D_{t-T}+\varepsilon_{p, t}$

\begin{tabular}{|c|c|c|c|c|c|}
\hline & & Small Size Portfolio & $\begin{array}{c}\text { Big Size } \\
\text { Portfolio }\end{array}$ & $\begin{array}{c}\text { Low BVE/MVE } \\
\text { Portfolio }\end{array}$ & $\begin{array}{c}\text { High BVE/MVE } \\
\text { Portfolio }\end{array}$ \\
\hline \multirow{3}{*}{ VWPD $_{\text {t-1 }}$} & coefficient & -0.024 & -0.013 & -0.028 & 0.002 \\
\cline { 2 - 6 } & t-statistic & -0.179 & -0.102 & -0.318 & 0.018 \\
\cline { 2 - 6 } & p-value & 0.859 & 0.919 & 0.751 & 0.986 \\
\hline \multirow{3}{*}{ VWPD $_{t-2}$} & coefficient & 0.236 & 0.288 & $0.352^{* *}$ & 0.135 \\
\cline { 2 - 6 } & t-statistic & 1.457 & 1.669 & 2.091 & 0.940 \\
\cline { 2 - 6 } & p-value & 0.148 & 0.098 & 0.039 & 0.349 \\
\hline \multirow{3}{*}{ VWPD $_{t-3}$} & coefficient & $-0.284^{*}$ & $-0.221^{*}$ & $-0.256^{*}$ & $-0.185^{*}$ \\
\cline { 2 - 6 } & t-statistic & -3.017 & -3.896 & -3.356 & -2.502 \\
\cline { 2 - 6 } & p-value & 0.003 & 0.000 & 0.001 & 0.014 \\
\hline
\end{tabular}

Model 2: $R_{p, t}=a+\beta R_{M, t}+s S M B_{t}+h H M L_{t}+c R_{p, t-1}+\sum_{T=1}^{3} p_{T} V W P D_{t-T}+\varepsilon_{p, t}$

\begin{tabular}{|c|c|c|c|c|c|}
\hline & & Small Size Portfolio & $\begin{array}{c}\text { Big Size } \\
\text { Portfolio }\end{array}$ & $\begin{array}{c}\text { Low BVE/MVE } \\
\text { Portfolio }\end{array}$ & $\begin{array}{c}\text { High BVE/MVE } \\
\text { Portfolio }\end{array}$ \\
\hline \multirow{3}{*}{ VWPD $_{\text {t-1 }}$} & coefficient & 0.012 & -0.058 & -0.089 & 0.077 \\
\cline { 2 - 6 } & t-statistic & 0.122 & -0.290 & -0.547 & 0.504 \\
\cline { 2 - 6 } & p-value & 0.903 & 0.772 & 0.585 & 0.615 \\
\cline { 2 - 6 } VWPD $_{t-2}$ & coefficient & 0.103 & 0.189 & 0.228 & 0.025 \\
\cline { 2 - 6 } & t-statistic & 1.332 & 0.966 & 1.162 & 0.206 \\
\hline \multirow{3}{*}{ VWPD $_{t-3}$} & p-value & 0.185 & -0.336 & 0.248 & -0.037 \\
\cline { 2 - 6 } & t-statistic & $-0.156^{* * *}$ & -2.407 & $-0.077 * * *$ & -2.442 \\
\cline { 2 - 6 } & p-value & -1.839 & 0.018 & 0.061 & 0.016 \\
\hline
\end{tabular}

Notes: The results are based on monthly data from 31/1/1997 to 31/12/2007. $\mathrm{R}_{\mathrm{p}, \mathrm{t}}$ is excess return for two extreme decile portfolios 1 and 10 sorted by size and book-to-market ratio; $\mathrm{R}_{\mathrm{M}, \mathrm{t}}$ is excess market return of the ASE; SMB and HML are the Fama-French mimicking risk factors; $\mathrm{R}_{\mathrm{p}, \mathrm{t}-1}$ is portfolio return lagged one month and is used to control for serial correlation in the dependent variable; and $\mathrm{VWPD}_{\mathrm{t}-\mathrm{T}}$ is the value weighted premium/discount lagged $\mathrm{T}$ months $(\mathrm{T}=1,2,3)$. When necessary, regression test statistics are based on standard errors corrected for conditional heteroscedasticity and autocorrelation of order $\mathrm{N}$ using the method in Newey and West (1987). The autoregressive lags were estimated by setting a maximum number of $\mathrm{N}=6$ and by choosing $\mathrm{N}$ which results in the minimum regression standard error. The superscripts $(*),(* *)$ and $(* * *)$ denote significance at the $1 \%, 5 \%$ and $10 \%$ levels respectively.

We then examined whether VWPD has the power to predict next-month reversals in the size and the BVE/MVE premiums. Table 6 reports these results. In particular, when using model 1 as our predictive regression model, Table 6 indicates that there was a significant negative relation between the VWPD and the expected size and BVE/MVE premiums. Unsurprisingly, when moving to model 2 the results change. Both the coefficient and the significance of VWPD drop to lower levels implying that its predictive power is not unconditional on the form of the predictive model. Moreover, VWPD is now insignificant in explaining the expected BVE/MVE premium. 
Table 6: The Significance Of VWPD In Predicting The Size And The Book-To-Market Premiums

$$
\text { Model 1: } R_{H, t}=a+c R_{H, t-1}+p V W P D_{t-1}+\varepsilon_{p, t}
$$

Model 2: $R_{H, t}=a+\beta R_{M, t}+s S M B_{t}+h H M L_{t}+c R_{H, t-1}+p V W P D_{t-1}+\varepsilon_{p, t}$

\begin{tabular}{|c|c|c|c|c|c|}
\hline & & \multicolumn{2}{|c|}{ Model 1} & \multicolumn{2}{|c|}{ Model 2} \\
\hline & & $\begin{array}{l}\text { Size Premium } \\
\text { (Small - Big) }\end{array}$ & $\begin{array}{c}\text { BVE/MVE } \\
\text { Premium } \\
(\text { High }- \text { Low })\end{array}$ & $\begin{array}{c}\text { Size } \\
\text { Premium } \\
(\text { Small - Big) } \\
\end{array}$ & $\begin{array}{c}\text { BVE/MVE } \\
\text { Premium } \\
\text { (High }- \text { Low })\end{array}$ \\
\hline \multirow{3}{*}{$\mathbf{V W P D}_{\mathrm{t}-1}$} & coefficient & $-0.116^{* *}$ & $-0.126^{*}$ & $-0.076^{* * *}$ & -0.031 \\
\hline & t-statistic & -2.399 & -3.230 & -1.965 & -0.933 \\
\hline & p-value & 0.018 & 0.002 & 0.052 & 0.352 \\
\hline \multirow{2}{*}{ LRT } & LRT-statistic & $6.033 * *$ & $10.264 *$ & $4.239 * *$ & 0.910 \\
\hline & p-value & 0.014 & 0.001 & 0.040 & 0.340 \\
\hline
\end{tabular}

Notes: The results are based on monthly data from $31 / 1 / 1997$ to $31 / 12 / 2007$. $\mathrm{R}_{\mathrm{H}, \mathrm{t}}$ is the return of two hedge portfolios which are long on small size and high book-to-market stocks and short on big size and low book-to-market stocks. These two hedge portfolios have been chosen to proxy for the size and the BVE/MVE premiums; $\mathrm{R}_{\mathrm{M}, \mathrm{t}}$ is excess market return of the ASE; SMB and HML are the Fama-French mimicking risk factors; $\mathrm{R}_{\mathrm{H}, \mathrm{t}-1}$ is portfolio return lagged one month and is used to control for serial correlation in the dependent variable; and $\mathrm{VWPD}_{\mathrm{t}-1}$ is the value weighted premium/discount lagged 1 month. When necessary, regression test statistics are based on standard errors corrected for conditional heteroscedasticity and autocorrelation of order $\mathrm{N}$ using the method in Newey and West (1987). The autoregressive lags were estimated by setting a maximum number of N=6 and by choosing $\mathrm{N}$ which results in the minimum regression standard error. LRT is the standard Likelihood Ratio Test which tests the hypothesis that the form of the model is well specified. The superscripts $(*),(* *)$ and $(* * *)$ denote significance at the $1 \%, 5 \%$ and $10 \%$ levels respectively.

However, the results of model 2 lose their importance when looking at the values of the LRT statistic reported in the bottom lines of Table 6 . These results indicate that the form of model 1 cannot be rejected at the 5 percent level of significance and hence our hypothesis that VWPD exhibits predictive power for reversals in the expected size and the BVE/MVE premiums is accepted at least at the 5 percent significance level.

\section{CONCLUSIONS AND IMPLICATIONS}

In this paper, we addressed the question of whether the premium/discount (PD) of closed-end funds is an adequate proxy for small investor sentiment in Greece. Using monthly data from 01/31/1997 to 12/31/2007, we found evidence that the PD exhibits some degree of explanatory power for the cross-section of contemporaneous portfolio returns, and particularly for the returns of big-size and low BVE/MVE portfolios. However, we also found that the PD exhibits little incremental information content over the mimicking risk factors of Fama and French (1993) and especially over the HML factor.

In terms of predictive ability, we tested whether the PD complies with the investor sentiment model, which predicts that periods of high sentiment are followed by periods of low stock returns. Our analysis showed that the $\mathrm{PD}$ has the power to explain near-term reversals in both the size and the BVE/MVE premiums. However, we found no robust evidence that it can predict near-term reversals in individual portfolio returns.

Overall, our results lend some support to the behavioral explanation of the PD anomaly. However, our results also suggest that the PD is not an accurate measure of small investor sentiment. Hence, our first implication calls for further research in the area to reveal better proxies of investor sentiment in Greece and more generally in emerging markets.

Another important implication of our results concerns the likely impact that sudden changes in sentiment may have on asset prices. In periods of unexpected financial crises, like the one we are experiencing at the present, it is difficult for rational arbitrageurs to promptly correct the impact of under-reaction on the level of asset prices. 
Therefore, regulators and market supervising authorities should be seriously concerned about the effects of small investor sentiment, especially if an abrupt drop in investor sentiment may translate, as Brown and Cliff (2005) argue, into a negative wealth shock which temporarily depresses economic activity.

\section{AUTHOR INFORMATION}

Dimitrios V. Kousenidis is assistant Professor of Finance at the Aristotle University of Thessaloniki, School of Economics, Department of Business Administration. He holds degrees in Economics, Finance and Accounting from the Aristotle University of Thessaloniki, Greece and from the University of Glasgow, Scotland, UK. Dr Kousenidis has extensive academic as well as professional experience both in the private and the public sector. His research interests revolve around accounting and capital markets, asset pricing and performance evaluation. Dr Kousenidis is the author of several scientific papers in accounting and finance which have been published in high quality peer reviewed academic journals in Europe and the USA.

Dimitrios I. Maditinos is assistant Professor of Information Technology, Finance and Financial Modelling at Kavala Institute of Technology, School of Business and Economics. He holds degrees in Business Administration with specialisation in Information Technology from Lund University, Sweden, and a PhD in Finance from the Business School, Greenwich University, UK. Before becoming a full academic he was working in senior position for Greek Productivity Centre as responsible for professional training in Information Technology and Management. His research interests are in financial modelling, performance measurement systems, investors' behaviour, financial information systems and electronic commerce.

Željko Šević is a Professor of Accounting, Finance and Public Policy and the Dean of the Caledonian Business School at Glasgow Caledonian University in Scotland. Prior to joining the Caledonian Business School in 2008, as the Head of the Division of Accounting, Finance and Risk, Professor Šević was the Professor of Accounting Finance and Public Policy in the University of Greenwich Business School, where he was also the Director of Research, Outreach and European Affairs. Professor Šević has extensive professional experience not only in academia, but also private, public and third sectors. He holds terminal degrees in Law and Financial Economics, is a professionally qualified accountant and certified fraud examiner. He has research interests revolving around the public sector and the application of business models in public sector organizations.

\section{REFERENCES}

1. Baker M.P. and Wurgler J., (2006) Investor sentiment and the Cross-Section of Stock Returns, Journal of Finance, 61, 1645-1680.

2. Baker M.P. and Wurgler J., (2007) Investor Sentiment in the Stock Market, Journal of Economic Perspectives, 21, 129-151.

3. Barberis N., Shleifer A. and Vishny R.W., (1997) A Model of Investor Sentiment, NBER Working Paper No 5926.

4. Banz R., (1981) The Relationship Between Return and Market Value of Common Stock, Journal of Financial Economics, 9, 3-18.

5. Berk J.B. and Stanton R., (2007) Managerial Ability, Compensation, and the Closed-End Fund Discount, Journal of Finance, 62, 529-556.

6. Bodurtha J. N., Kim D.S and Lee C.M.C., (1995) Closed-End Funds and U.S. Market Sentiment, Review of Financial Studies, 8, 879-918.

7. Brown G.W., (1999) Volatility, Sentiment, and Noise Traders, Financial Analysts Journal, 55, 82-90.

8. Brown G.W. and Cliff M.T., (2004) Investor Sentiment and the Near-Term Stock Market, Journal of Empirical Finance, 11, 1-27

9. Brown G.W. and Cliff M.T., (2005) Investor Sentiment and Asset Valuation, Journal of Business, 78, 405440.

10. Brown S., Goetzmann W.N., Hiraki T., Shiraishi N. and Watanabe M., (2002) Investor Sentiment in Japanese and U.S. Daily Mutual Fund Flows, Yale ICF Working Paper No. 02-09. 
11. Calvet L.E., Campbell J.Y. and Sodini P., (2008) Fight or Flight? Portfolio Rebalancing by Individual Investors, NBER Working Paper No. W14177.

12. Chen N.F, Kan R. and Miller M.H., (1993a) Are the Discounts on Closed-End Funds a Sentiment Index?, Journal of Finance, 48, 795-800.

13. Chen N.F, Kan R. and Miller M.H., (1993b) Yes, Discounts on Closed-End Funds are a Sentiment Index: A Rejoinder, Journal of Finance, 48, 809-810.

14. Cherkes M., Sagi J. and Stanton R., (2009) A Liquidity-Based Theory of Closed-End Funds, Review of Financial Studies, 22, 257-297.

15. Chopra N., Lee C.M.C., Shleifer A. and Thaler R.H. (1993a) Yes, Discount on Closed-End Funds Are a Sentiment Index, Journal of Finance, 48, 801-808.

16. Chopra N., Lee C.M.C., Shleifer A. and Thaler R.H., (1993b) Summing Up, Journal of Finance, 48, 811812 .

17. DeBond W. and Thaler R., (1987) Further Evidence on Investor Overreactions and Stock Market Seasonality, Journal of Finance, 42, 557-581.

18. DeLong J.B., Shleifer A., Summers L.H. and Waldman R., (1990) Noise Trader Risk in Financial Markets, Journal of Political Economy, 98, 703-738.

19. Dimson, E., and C. Minio-Paluello (2002) The Closed-End Fund Discount, Working Paper, London Business School.

20. Doukas J.A. and Milonas N.T., (2004) Investor Sentiment and the Closed-End Funds Puzzle: Out-ofSample Evidence, European Financial Management, 10, 235-266.

21. Edmans A., Garcia D. and Norli, Ø., (2007) Sports Sentiment and Stock Returns, Journal of Finance, 62, 1967-1998.

22. Elton E.J., Gruber M.J. and Busse J.A., (1998) Do Investors Care about Sentiment?, Journal of Business, 71, 477-500.

23. Elton E.J., Gruber M.J. and Busse J.A., (2004) Are Investors Rational? Choices among Index Funds, Journal of Finance, 59, 261-288.

24. Fama E., (1998) Market Efficiency, Long-Term Returns and Behavioral Finance, Journal of Financial Economics, 49, 283-306.

25. Fama E. and French K., (1992) The Cross-Section of Expected Stock Returns, Journal of Finance, 47, 427465.

26. Fama E. and French K., (1993) Common Risk Factors in the Returns on Stocks and Bonds, Journal of Financial Economics, 33, 3-56.

27. Gemmill G. and Thomas D., (2000) Sentiment, Expenses and Arbitrage in Explaining the Discount on Closed-End Funds, Working Paper, City University Business School.

28. Gerber A., Hens T. and Vogt B., (2002) Rational Investor Sentiment, Zurich IEER Working Paper No. 126.

29. Halkos G.E. and Krintas T.N., (2006) Behavioral and Fundamental Explanations of Discounts on ClosedEnd Funds: An Empirical Analysis, Applied Financial Economics, 16, 395-404.

30. Hardouvelis G.A., Angelidis T.T. and Tsiritakis E.D., (2004) Greek Closed-End Fund Premia: An Empirical Investigation, Working Paper, University of Piraeus - Greece (available on www.ssrn.com)

31. Kumar A. and Lee C.M.C., (2003) Individual Investor Sentiment and Comovement in Small Stock Returns, Working Paper, Cornell University.

32. Lakonishok J., Shleifer A. and Vishny R.W., (1994) Contrarian Investment, Extrapolation and Risk, Journal of Finance, 49, 1541-1578.

33. Lee C.M.C., Shleifer A. and Thaler R.H., (1990) Anomalies: Closed-End Mutual Funds, Journal of Economic Perspectives, 4, 153-164.

34. Lee C.M.C., Shleifer A. and Thaler R.H., (1991) Investor Sentiment and the Closed-End Fund Puzzle, Journal of Finance, 46, 75-109.

35. Leonard D. and Shull D., (1996) Investor Sentiment and the Closed-End Fund Evidence: Impact of the January Effect, Review of Economics and Finance, 36, 117-126.

36. Levis M. and Thomas D.C., (1999) Country Funds and Investor Sentiment: UK and US Evidence, Working Paper, City University Business School.

37. Ljungqvist A.P., Nanda V. and Singh R., (2006) Hot Markets, Investor Sentiment, and IPO Pricing, Journal of Business, 76, 1667- 1702. 
38. Maditinos D.I., Sevic Z. and Theriou N.G., (2007) Investors' Behavior in the Athens Stock Exchange, Studies in Economics and Finance, 24, 32-50.

39. Merikas A.A., Merikas A.G., Vozikis G.S. and Prasad D., (2004) Economic Factors and Individual Investor Behavior: The Case of the Greek Stock Exchange, Journal of Applied Business Research, 20, 93-98.

40. Neal R. and Wheatley S.M., (1998) Do Measures of Investor Sentiment Predict Returns?, Journal of Financial and Quantitative Analysis, 33, 523-547.

41. Newey W. K. and West K.D, (1987) A Simple, Positive Semi-definite, Heteroscedasticity and Autocorrelation Consistent Covariance Matrix, Econometrica, 55, 703-708.

42. Papaioannou G.I., Safieddine A., Travlos N.G. and Philippas N.D., (1997) The Market and Operating Performance of Firms that Go Public in the Athens Stock Exchange, Working Paper, University of Piraeus (in Greek).

43. Severn A.K., (1998) Closed-End Funds and Sentiment Risk, Review of Financial Economics, 7, 103-119.

44. Simpson M.W. and Ramchander S., (2002) Is Differential Sentiment a Cause of Closed-End Country Fund Premia? An Empirical Examination of the Australian Case, Applied Economics Letters, 9, 615-619.

45. Wang A., (2000) Overconfidence, Investor Sentiment, and Evolution, Working Paper, Rice University.

\section{ENDNOTES}

${ }^{1}$ As Baker and Wurgler (2006, p. 1648) support, this definition assumes that sentiment is the power that drives the relative demand for speculative investments. Therefore, sentiment can cause cross-sectional effects even when arbitrage forces are the same across stocks.

${ }^{2}$ Another line of research examines the importance of sentiment risk, however, without directly relating it to the closed-end fund PD. For a review of such studies, see: Barberis, Shleifer and Vishny (1997), Wang (2000) and Kumar and Lee (2002).

${ }^{3}$ In a later paper, Elton et al (2004) show that in the index fund market, where rational arbitrage is impossible, irrational behavior dominates the setting of equilibrium market prices, implying that in the absence of arbitrage opportunities sentiment risk may be a significant risk factor.

${ }_{5}^{4}$ Financial sector firms have been excluded from our sample because of their extremely low BVE/MVE ratios.

${ }^{5}$ These results are not reported here, but they are available on request. 


\section{$\underline{\text { NOTES }}$}

